\title{
Variation in Self-Perception of Professional Competencies in Systems Engineering Students, due to the COVID -19 Pandemic
}

Teodoro Díaz-Leyva ${ }^{*}, 1$, Nestor Alvarado-Bravo², Jorge Sánchez-Ayte ${ }^{1}$, Almintor Torres-Quiroz ${ }^{2}$, Carlos Dávila-Ignacio ${ }^{1}$, Florcita Aldana-Trejo ${ }^{3}$, José Razo-Quispe ${ }^{3}$, Omar Chamorro-Atalaya ${ }^{1}$

${ }^{1}$ University National Technological of Lima Sur, Faculty of Engineering and Management, Lima, Peru

${ }^{2}$ University National of Callao, Faculty of Chemical Engineering and Faculty of Economic Sciences, Callao, Peru

${ }^{3}$ San Juan Bautista Private University, Faculty of Communication and Administrative Sciences, Lima, Peru

A R T I C LE INFO

Article history:

Received: 08 January, 2021

Accepted: 11 February, 2021

Online: 16 February, 2021

Keywords:

Self-perception

Professional skills

Students

Systems engineer

Covid-19

\begin{abstract}
A B S T R A C T
The objective of this article is to determine if the self-perception of professional competences has been affected, in systems engineering students, during the health emergency declared in Peru by Covid-19; The results will allow the public university of Peru to make corrective decisions and formulate proposals to improve the functioning of the variable under study. Initially, the comparative analysis was carried out, where it is observed that in the academic semester 2020-I (during the health emergency), there is a greater number of students who present a better self-perception of the 10 indicators of the professional skills dimension, compared to the semester 2019-II (before the health emergency). Likewise, the indicators "To solve problems and cases of the specialty" and "To master practical professional skills" present a higher rate of improvement in selfperception, of $8.14 \%$ and $10.37 \%$, respectively. Finally, when carrying out the statistically validation of the association of the two mentioned indicators, using the contingency table, it is observed, by the Chi-square statistic, a significance (bilateral) lower than $\alpha=0.05$, with this, it is verified, the significant association of the indicators; This is supported by the percentage obtained in the contingency table, where it is shown that $90.6 \%$ of the systems engineering students in the 2019-II semester and 95.5\% of the students in the 2020I semester, who are satisfied with the indicator "To master practical professional skills", have experienced a positive impact with the indicator "To solve problems and cases of the specialty".
\end{abstract}

\section{Introduction}

A commonly perceived scenario in many universities in Latin American countries is one in which students who graduate from their professional careers do not seem to be sufficiently prepared for the challenges that arise in real life; In this regard in [1], the author highlights that many students lack skills that allow them to take risks, organize and go beyond what they have learned in class.

That is why it is almost necessary for the model in which the teacher is the center of attention in a class, to be totally displaced. In this regard, in [2], the author states that emphasis should be

\footnotetext{
${ }^{*}$ Corresponding Author: Teodoro Díaz-Leyva, Edif. R Dpto. 202 Sec.I A.M.C, Ventanilla, Lima, 982716223, isdiazl@hotmail.com
}

placed on the figure of the teacher as a tutor or facilitator, and the center of attention in a class session should be on the student, on their ability to learn and learn by doing; hence, many universities have redefined the teaching objectives in terms of competencies.

In [3], the author points out that in the context of education in which we find ourselves, the great paradigm that students face is to move from traditional models in learning processes, towards more open models in which the student is part of their own learning process.

In this regard, in [4], the author points out that university higher education currently poses multiple challenges, among them: raising quality, relevance, equity, greater links with the community 
and emphasis on research; all this obtained from the competences that students are acquiring in their professional training period.

From a general perspective in relation to professional competences, in [5], the author affirms that when the professional competencies that a student must acquire to carry out a task are investigated, not only those inherent to knowledge are recreated, knowledge or particular practice, but those that are linked to thoughts; therefore, controlling the former will make the latter more efficient.

In relation to the aforementioned, in [6], the author establishes that a professional competence is the set of skills, attitudes and responsibilities that describe the learning outcomes of a subject or educational program, which enable the student to develop a professional activity.

In [7], the author points out that changes in the world of work, information management processes and knowledge production, ways of knowing and researching, characteristics of today's society, traversed by ICT (Technology of Information and Communication), permanently generate new training needs that the classroom and the university do not always seem to be able to satisfy.

In [8], the author points out that higher education institutions that are in charge of training systems engineering professionals must remain attentive to the reality of their environment and continually verify the profile of their graduates to be trained; since the contents based on technological tools are quite changeable over time.

Another outstanding contribution in relation to the competences in the training of students in systems engineering is indicated in [9], so that systems engineers are prepared to take on the challenges of the new knowledge society that they express in their mission, they must possess skills to transmit information, select the ideal medium, possess skills in the use of ICT, ability to select and classify information, among others.

In this regard in [10], the author specifies that in order for university students to have a positive perception in relation to the professional skills acquired during their university days, these must represent tools that allow them to effectively face the challenges that await them, giving significant contribution to society.

In [11], the author defines the university student's selfperception as the way in which he perceives himself within the educational process. Also in [12], the author points out that the university student's self-perception indicates how the student or students feel about themselves, how they see themselves in the field they are developing.

Perhaps all of the above is seen from a non-pandemic context, with classroom development in person, making use of laboratories or equipment installed at the University; However, today we are in the midst of a Covid-19 pandemic; In this regard in [13], the author points out that the unexpected expansion of Covid-19 has forced university classes to take place virtually or not in person in many countries, which at a certain point results in knowing whether through These platforms the student manages to develop the professional competences, typical of the professional career of systems engineering.

In this sense, the objective of this article is to carry out a comparative analysis of the variation of the self-perception of students of the systems engineering professional career of the academic semesters before (2019-II) and after (2020-I) the declared health emergency in Peru due to Covid-19. In addition, to identify which were the indicators that make up the self-perception variable that have experienced a greater impact on their satisfaction; whose association validation will be carried out through contingency tables.

\section{Investigation methodology}

\subsection{Research design}

The design is non-experimental, of a cross-sectional type, because the variable is studied simultaneously in a single year, in a single time, in which the survey of students from the 7th to the 10th cycle the Public University of Peru. The diagram that presents the cross-sectional design under study is as follows. It should be noted that the data collection period is carried out at different times, and at different samples, because the number of students surveyed is not the same in the 2019-II semester, as in the 2020-I semester.

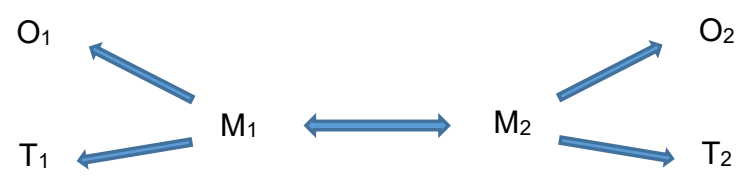

Figure 1: Research design

where:

M1 and M2, represent the systems engineering students of the academic semester 2019-II and academic semester 2020-I, respectively

$\mathrm{T} 1$ and T2, represent the data collection period, both in the academic semester 2019-II, and in the academic semester 2020-I

$\mathrm{O} 1$ and $\mathrm{O} 2$, represents the observation made of the selfperception of the professional competencies of systems engineering students, both in the 2019-II semester and in the 2020I semester.

\subsection{Research level}

The research level is descriptive, because the variables are not altered, and what is intended to be highlighted are the aspects related to the variation of the self-perception of those of the professional competences established in Public University located in Peru satisfaction survey, which was validated in [14].

\subsection{Population and sample}

The population is made up of students from the 7th to the 10th cycle Public University, in both the 2019-II and 2020-I semesters; Likewise, the sample is made up of all students, these being 149 and 140, students respectively; because there is no equality in the number of students per semester, the sample is not the same; It 
should be noted that, as it is the mandatory survey at Public University of Peru, it has been carried out on all students.

\subsection{Data Collection Technique and Instrument}

The data collection, as indicated in [15], it is carried out by applying the instrument, using various techniques or tools, for this case the survey technique is used and the instrument is the questionnaire, 6 dimensions are established (professional competencies, teaching staff, library services, administrative services of the faculty and professional school, university support service and personal and social attitudes), which will identify student satisfaction in the education Public University of Peru. In this research, the dimension "professional competences" has been chosen.

Data collection, as indicated in [16], is a selective process since it cannot be all-encompassing; Given the aforementioned, it is established that the sample is composed of students from the 7th to the 10th cycle Public University of Peru both in the 2019-II and 2020-I semester; Regarding this, in [17] it is pointed out that the results are more valid when the survey is applied to students in the last cycles, because they are more aware of the understanding of the competences they must acquire.

Likewise, the data collected were processed and transformed, initially using the scale of attitudes and opinions, known as the Likert scale; Since the questionnaire has two self-perception options to choose from, these being unsatisfied and satisfied, each one was valued with the numeral 1 and 2, respectively.

To carry out the data analysis, initially the validation test of the data collection instrument will be carried out by means of the SPSS software, then the comparative analysis of the results will be carried out using the Microsoft Excel software, finally, to carry out the validation of the data. association of the indicators, the contingency table that indicates the Chi-Square value will be used, this test is performed with the SPSS software.

\section{Results of the Investigation}

\subsection{Validation of the data collection instrument}

There are various models of reliability, for this research we will use Cronbach's Alpha, as indicated in [18], this model is based on the correlation between the study variables, through this test, it will be demonstrated statistically by means of the software IBM SPSS $\mathrm{V} 25$, that the data collection instrument, which is applied is reliable. This test has established the following criteria:

- $0.9-1=$ The measuring instrument is excellent

- Between $0.89-0.8=$ The measuring instrument is very good

- Between $0.79-0.7=$ The measuring instrument is acceptable

- Between $0.69-0.6=$ The measuring instrument is weak

- Between $0.59-0.5=$ The measuring instrument is poor

- $<0.5=$ The measuring instrument is not acceptable

Table 1: Reliability Analysis

\begin{tabular}{|c|c|}
\hline \multicolumn{2}{|c|}{ Reliability statistics } \\
\hline Cronbach's alpha & N of elements \\
\hline .894 & 20 \\
\hline
\end{tabular}

As can be seen in table 1, the Cronbach's Alpha coefficient is equal to 0.894 , this means that the data collection instrument is very good, therefore, its use and the data collected are reliable. It should be noted that the number of elements equal to 20 corresponds to the 10 indicators of the "professional competences" dimension, both for the 2019-II and 2020-I semesters.

\subsection{Comparing indicators that are part of professional skills}

At this point, the results that respond to the objective of this article are shown, which is to perform a comparative analysis of the variation of the self-perception of students of the systems engineering professional career of the academic semesters before (2019-II) and after (2020-I) of the health emergency declared in Peru by Covid-19.

Initially, in figure 2, the results of the self-perception of the professional competences dimension and its 10 indicators are presented; These results belong to the 149 systems engineering students from the 2019-II academic semester, before the health emergency declared in Peru by Covid-19, and when the classes were held in person.

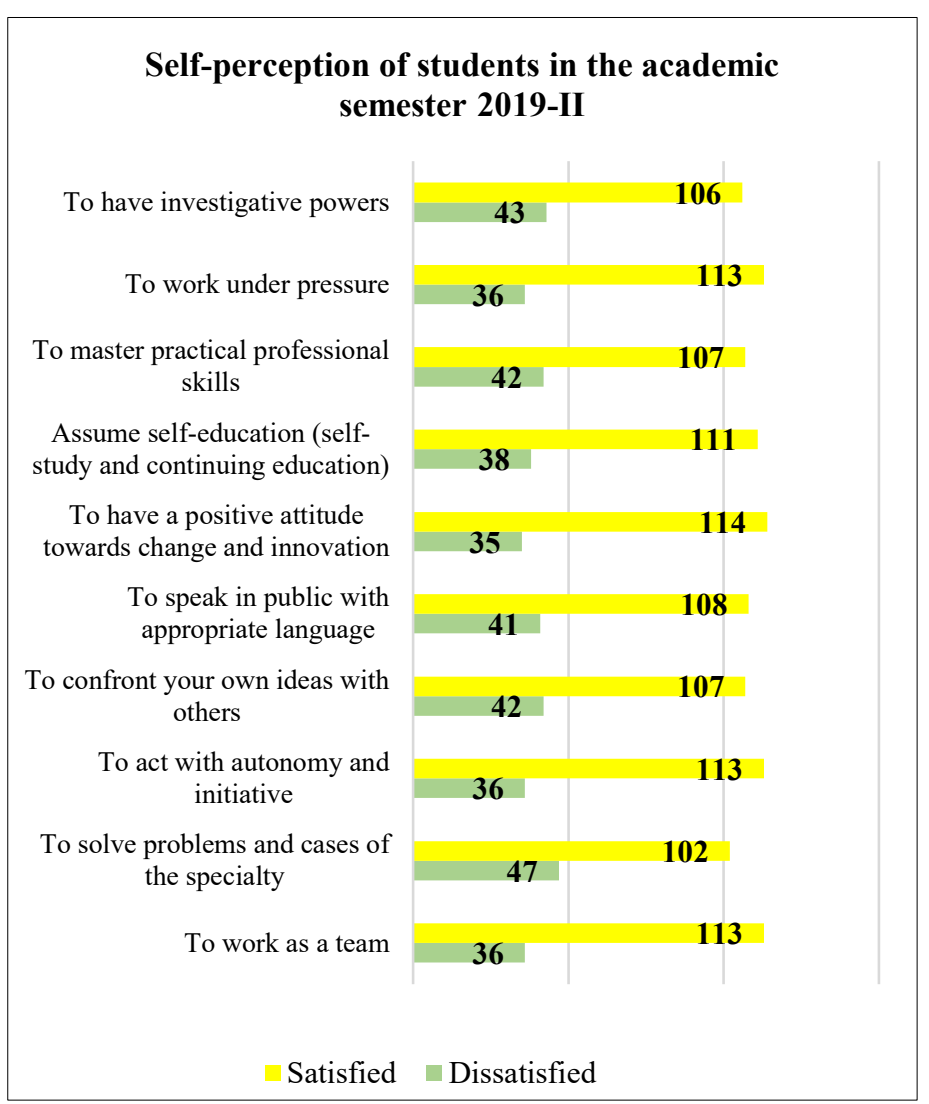

Figure 2: Self-perception of students in the academic semester 2019-II

Next, in the following figure 3 , the results of the selfperception of the professional competences dimension and its 10 indicators are presented; These results belong to the 140 systems engineering students of the 2020-I academic semester, during the health emergency declared in Peru by the Covid-19, and when the classes were held virtually or not in person. 




Figure 3: Self-perception of students in the academic semester 2019-II

As shown in the results obtained (figure 2 and 3 ) in the systems engineering career, in the $2020-\mathrm{I}$ semester, there is a greater number of students who present a better self-perception of the 10 indicators of the professional competences dimension, compared to the academic semester 2019-II, where there was no health emergency declared in Peru by Covid-19, and classes were held in person.

\subsection{Identifying the two indicators with the highest increase post Covid-19 pandemic}

Continuing with the research, and once the number of students with a better self-perception of the professional competences dimension has been determined in the comparative analysis, both in the academic semester 2019-II and in the semester 2020-I; Through the results obtained, we proceed to identify the indicators that make up the professional competences variable, which have experienced a greater increase in satisfaction, post-Covid-19 pandemic. These results are shown in Table 2.

Table 2 shows that, in the systems engineering career, in the 2020-I semester, during the Covid-19 pandemic, students have experienced a greater impact of the satisfaction of the indicators "To solve problems and cases of the specialty" and "To master practical professional skills"; As can be seen, the satisfaction index for these two indicators has improved by $8.14 \%$ and $10.37 \%$, respectively. It should be noted that this test counts the number of students who coincide with the perception of satisfaction of the indicators, therefore, the total sample is not reached.
Table 2: Percentage of variation of the variable self-perception of professional competences

\begin{tabular}{|c|c|c|c|}
\hline & & $\begin{array}{c}\text { To solve problems } \\
\text { and cases of the } \\
\text { specialty }\end{array}$ & $\begin{array}{c}\text { To master practical } \\
\text { professional skills }\end{array}$ \\
\hline $\begin{array}{c}7 \\
\text { ¿े̀n }\end{array}$ & Satisfied & 102 & 107 \\
\hline \multirow{2}{*}{} & \% Satisfied & $71.14 \%$ & $72.48 \%$ \\
\hline \multirow{2}{*}{} & Satisfied & 111 & 116 \\
\hline \% OF VARIATION & $8.14 \%$ & $82.86 \%$ \\
\hline
\end{tabular}

Figure 4 shows the increase in these two indicators.

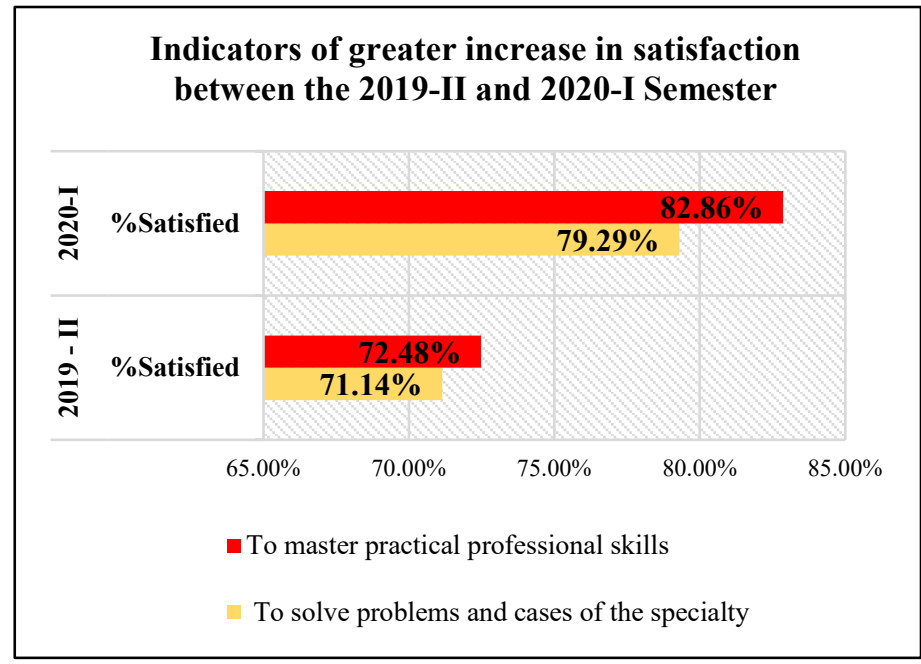

Figure 4: Indicators with the greatest increase in satisfaction (2019-II - 2020-I)

\subsection{Analysis of indicators through contingency table}

Once the results are obtained, at this point the statistical validation of the association between the two indicators with the greatest increase in satisfaction in the systems engineering career is carried out, during the Covid-19 pandemic; These indicators are "To solve problems and cases of the specialty" and "To master practical professional skills".

This validation is carried out using the IBM SPSS V25 statistical software, in which the contingency table tool will be used.

It should be noted that the contingency table is used to validate an association between two variables, and thus, to test the hypothesis. In this sense, once the indicators with the greatest increase in satisfaction after the Covid-19 pandemic have been identified, the null ( $\mathrm{Ho}$ ) and alternative ( $\mathrm{Ha}$ ) hypotheses of the research are established.

Ho: Mastering practical professional skills does not allow problem solving and specialty cases in systems engineering students.

Ha: Mastering practical professional skills allows students to solve problems and specialty cases in systems engineering. 
Table 3 shows the validation results of the association of the indicators in the 2019-II semester.

Table 3: Contingency table of the association of the indicators with the greatest increase in satisfaction in the 2019-II semester

\begin{tabular}{|l|r|r|r|}
\hline & Value & gl & \multicolumn{1}{|c|}{$\begin{array}{c}\text { Significance } \\
\text { (bilateral) }\end{array}$} \\
\hline Pearson's Chi-square & 60.217 & 1 & .000 \\
\hline Likelihood ratio & 57.117 & 1 & .000 \\
\hline N of valid cases & 149 & & \\
\hline
\end{tabular}

Likewise, table 4 shows the validation results of the association of the indicators in the 2020-I semester.

Table 4: Contingency table of the association of the indicators with the greatest increase in satisfaction in the 2020-I semester

\begin{tabular}{|l|r|r|r|}
\hline & Value & gl & \multicolumn{1}{|c|}{$\begin{array}{c}\text { Significance } \\
\text { (bilateral) }\end{array}$} \\
\hline Pearson's Chi-square & 60.259 & 1 & .000 \\
\hline Likelihood ratio & 50.145 & 1 & .000 \\
\hline N of valid cases & 140 & & \\
\hline
\end{tabular}

As can be seen in Table 3 and 4, the value of the Chi-square statistic is 60.217 and 60.259 , respectively, and the likelihood ratio 57.117 and 50.145, as established by different authors, if these values differ significantly from 5 for levels of significance greater than 0.05 , it is stated that there is an association. Likewise, the significance (bilateral) of Chi-square is less than $\alpha=0.05$, due to this, the null hypothesis is rejected, thereby accepting the alternative hypothesis.

As the value of $\mathrm{p}$ is less than 0.05 , it is shown that there is a significant association between the two indicators; Therefore, table 5 shows the percentage of satisfaction between the association of the analyzed indicators, for the 2019-II semester.

Table 5: Contingency table of the percentage of satisfaction among the indicators with the greatest increase in satisfaction in the 2019-II semester

\begin{tabular}{|c|c|c|c|c|}
\hline \multicolumn{4}{|c|}{ Contingency table } \\
\hline \multicolumn{2}{|c|}{$\%$ within to solve problems and cases of the specialty } \\
\hline \multicolumn{2}{|c|}{} & \multicolumn{2}{|c|}{$\begin{array}{l}\text { To master practical } \\
\text { professional skills }\end{array}$} & \multirow{2}{*}{ Total } \\
\cline { 2 - 4 } & Dissatisfied & Satisfied & \\
\hline $\begin{array}{c}\text { To solve } \\
\text { problems } \\
\text { and cases of } \\
\text { the } \\
\text { specialty }\end{array}$ & Dissatisfied & $72.1 \%$ & $27.9 \%$ & $100.0 \%$ \\
\cline { 2 - 5 } & Satisfied & $9.4 \%$ & $90.6 \%$ & $100.0 \%$ \\
\hline \multicolumn{2}{|c|}{ Total } & $27.5 \%$ & $72.5 \%$ & $100.0 \%$ \\
\hline
\end{tabular}

In the same way, supporting the result, Table 6 shows the percentage of satisfaction between the association of the analyzed indicators, for the 2020-I semester.
Table 6: Contingency table of the percentage of satisfaction among the indicators with the greatest increase in satisfaction in the 2020-I semester

\begin{tabular}{|c|c|c|c|c|}
\hline \multicolumn{4}{|c|}{ Contingency table } \\
\hline \multicolumn{2}{|c|}{$\%$ within to solve problems and cases of the specialty } \\
\hline \multicolumn{2}{|c|}{} & \multicolumn{2}{|c|}{$\begin{array}{c}\text { To master practical } \\
\text { professional skills }\end{array}$} & \multirow{2}{*}{ Total } \\
\cline { 3 - 4 } & Dissatisfied & Satisfied & \\
\hline $\begin{array}{c}\text { To solve } \\
\text { problems } \\
\text { and cases of } \\
\text { the } \\
\text { specialty }\end{array}$ & Dissatisfied & $65.5 \%$ & $34.5 \%$ & $100.0 \%$ \\
\cline { 2 - 4 } & Satisfied & $4.5 \%$ & $95.5 \%$ & $100.0 \%$ \\
\hline \multicolumn{2}{|c|}{ Total } & $17.1 \%$ & $82.9 \%$ & $100.0 \%$ \\
\hline
\end{tabular}

As shown in table 5 and $6,90.6 \%$ and $95.5 \%$ of systems engineering students who are satisfied with the indicator "To master practical professional skills", have experienced a positive impact with the indicator " To solve problems and cases of the specialty".

Through these results, it can be stated that there is a significant association between the indicators; establishing that students of systems engineering by mastering practical professional skills, can solve problems and cases of the specialty.

\section{Discussion of results}

It is important to indicate that the systems engineering career was chosen, for the present investigation why in the context of the pandemic it was sought to determine the impact, on student satisfaction, with respect to the dimension of self-perception of acquired competences, taking into account that the development of it, lies in its vast majority in the use of a PC.

Given the development of the research, it was obtained that, in the systems engineering career, in the 2020-I semester, during the Covid-19 pandemic, there is a greater number of students who present, a better satisfaction of the 10 indicators of the professional competences dimension, compared to the academic semester 2019-II; This is supported by the fact that, in the face-to-face classes, it was evident that the laboratories were deficient in terms of the number of computers per student, therefore, the practical learning of the subjects was not the most efficient, while in the context After the pandemic, each student uses their own PC at home, thus achieving greater use of the software used.

What is described in the previous paragraph reaffirms the following result, which reveals that, in the systems engineering career, in the 2020-I semester, during the Covid-19 pandemic, students have experienced a greater impact of the satisfaction of the indicators "To solve problems and cases of the specialty" and "To master practical professional skills"; As can be seen in table 2, the satisfaction index for these two indicators has improved by $8.14 \%$ and by $10.37 \%$.

In relation to the indicators obtained, in [19], it is pointed out that to obtain an ideal professional performance, the specialty problems that are most often presented to the student must be taken into account, as well as the contents and tools that are counted for the development of the subjects; the correct handling of it must be visualized in the integration of knowledge that allows the student 
to solve professional problems according to their rigor and complexity; Likewise, the academic organization provided by the educational institution in relation to the environment with which the professional counts for its development, allows the teacher to efficiently carry out his evaluation of said professional competencies.

Due to the (bilateral) significance of Chi-square is less than $\alpha$ $=0.05$, it can be verified statistically that there is a significant association between the analyzed indicators, with this it can be affirmed that systems engineering students have mastered practical professional skills, can solve specialty problems and cases. Regarding this, in [20] it is indicated that universities must integrate in their academic decisions, plans that allow keeping the contents taught in classrooms up to date, as well as tools for their development, in order to keep up with what the labor market dictates; For example, the student by learning properly, the programming languages most used for the design of solution software or tools mostly used in communication networks of companies, will be able to solve problems and cases of the specialty, thus managing to face the problem. working market.

Reaffirming everything described, the results expressed in the contingency table indicate that $90.6 \%$ of the systems engineering students in the academic semester 2019-II and $95.5 \%$ of the students in the 2020-I semester, who are satisfied with the indicator "To master practical professional skills", have experienced a positive impact with the indicator "To solve problems and cases of the specialty".

\section{Conclusions}

When carrying out the comparative analysis of the variation in the self-perception of students of the systems engineering career of the academic semesters before (2019-II) and after (2020-I) of the health emergency declared in Peru by Covid-19, it is concluded that in the systems engineering career, in the 2020-I semester, there is a greater number of students who present a better satisfaction of the 10 indicators of the professional competencies dimension, compared to the 2019-II academic semester.

When carrying out the identification of the indicators that make up the self-perception variable, which have experienced a greater impact on their satisfaction, it is concluded that the indicators "To solve problems and cases of the specialty" and "To master practical professional skills" present a higher index improvement in satisfaction, of $8.14 \%$ and $10.37 \%$, respectively.

When carrying out the validation of the association of the indicators that have experienced a greater impact on their satisfaction, through contingency tables, it is concluded that $95.5 \%$ of the students who are satisfied with the indicator "To master professional skills practices", have experienced a positive impact with the indicator "To solve problems and cases of the specialty". Likewise, the Chi-square statistic gives us a (bilateral) significance lower than $\alpha=0.05$, due to this, the significant association of the indicators is statistically verified, stating that systems engineering students by mastering practical professional skills they can solve specialty problems and cases.

\section{Conflict of Interest}

The authors declare no conflict of interest.

\section{Acknowledgment}

The authors thank the work team for their contribution in the development of this article.

\section{References}

[1] V. Flores, Scientific Competences and Educational Quality of Students in the Professional School of Systems Engineering, Thesis, University National of Education, 2019.

[2] M. Pinto, D. Guerrero-Quesada, "How Spanish university students perceive informational competences: a case study," Investigation Librarian, 31(73), 213-236, 2017, doi: dx.doi.org/10.22201/iibi.24488 321xe.2017.7 3.57854.

[3] M. Gonzales-Alonso, R. Fernandez-Diáz, M. Simon-Martin, "Evolution of the self-perception of the level of acquisition of competences of the students of an engineering degree subject," Childhood, Education and Learning, 3(2), 441-447, 2017, doi: 10.22370/ieya.2017.3.2.762

[4] J. Larrea, L. alonso, R. Tejeda, "Strategy for the evaluation of professional competencies in students of systems engineering," Electronic Journal Training and Educational Quality, 5(2), 17-32, 2017, doi: http://refcale.uleam.edu.ec/index.php/refcale/article/view/1114.

[5] A. Mortigo, D. Rincón, "Emotional competences in higher education students: self-perception and demographic correlation," University of Rioja, 10(21), 430-448, 2018, doi: https://dialnet.unirioja.es/servlet/artic ulo? codigo $=6934960$.

[6] I. Cruz, SICPE Information Systems for the Continuous Evaluation of the Achievement of the profile of the graduate of the Systems Engineering career, Thesis, University Peruvian Union, 2017.

[7] S. Fulgueira, Information systems teachers' competencies in educational processes measured by technologies for the development of professional competences in industrial engineering, Thesis, University National of Cordova, 2017.

[8] C. Martínez, "Certification model based on competencies for the career of engineering in computer systems in El Salvador," Journal Inventum, 11(21), 2016, doi:10.26620/uniminuto.inventum.11.21.2016.

[9] L. Coronel-Rojas, "Selection and use of information as generic competencies in the professional training of systems engineers," Journal Perspectives, 2(1), 6-17, 2017, doi:10.22463/25909215.1280.

[10] M. Perez, A. Tufiño, "Teleeducation and Covid-19," CienciAmerica Journal, 9(2), 58-64, 2020, doi:10.33210/ca.vgi2.296.

[11] U. Ramírez, J. Barragaán, "Self-perception of university students on the use of digital technologies for learning," Apertura Journal, 10(2), 94-109, 2018, doi: 10.32870/Ap.v10n2.1401.

[12] L. Dunai, J. Alfonso, I. lengua, G. Peris-Fajarnés. Tufiño, "Study of the selfperception of academic performance of first year university students," INNODOCT 2018, 4(1), 905-910, 2018, doi: 10.4995/TNN201 8.2018.8906.

[13] I. Panadero, C. Bocos, J. Sevillano, "From face-to-face to virtual in labs: the good, the ugly and the bad," CIVINEDU 2020, 4(1), 54-55, 2020, doi: http://www.civinedu.org/wp-conten/tuploads/2020/11/C IVINEDU2020.

[14] E. Gallardo, "Investigation methodology," Huancayo: University Continental, 72, 2017, ISBN 978-612-4196-

[15] F. Arias, "The research project," Mercantil: Episteme, 7, 76, 2016, ISBN 980-07-8529-9

[16] M. Tobón, M. Durán, A. Áñez, "Academic and professional satisfaction of university students," REDHECS Electronic journal of Humanities, Education and Social Communication, 11(22), 110-129, 2016, ISSN-e 18569331

[17] J. Rodríguez-Rodríguez, M. Reguant-Álvarez, "Calculate the reliability of a questionnaire or scale using the SPSS: Cronbach's alpha coefficient," REIRE Revista d'Innovació i Recerca en Educació, 13(2), 1-13, 2019, https://doi.org/10.1344/reire2020.13.230048

[18] R. Ramírez-Fernández, J. Machado-Licona, O. Fernández-Ramírez, "Evaluation of professional competences in university students," 8th International Scientific Conference, University of Holguín

[19] R. Ramírez-Fernández, J. Machado-Licona, O. Fernández-Ramírez, "Quality in university education, from the systems engineering program: a qualitative vision of higher education," Amphibian Scientific Journal, 2(2), 41-50, 2019, https://doi.org/10.37979/afb.2019v2n2.49 